\title{
Dêixis e estranhamento: caminhos da nova poesia brasileira
}

\author{
Myriam Ávila \\ Universidade Federal de Minas Gerais/CNPq
}

\begin{abstract}
RESUMO: A PERCEPÇÃO VISUAL DO MUNDO, QUE SE DETALHA EM NUANÇAS DE FORMAS, CORES E MOVIMENTOS, É UM VEIO POUCO EXPLORADO NA POESIA BRASILEIRA, EM CONTRASTE, POR EXEMPLO, COM A NORTE-AMERICANA. A FUGA DA SUBJETIVIDADE POR MEIO DA CISÃO ENTRE O VEDOR E O VISTO, ENTRE O OBJETO E A MÁQUINA-POETA QUE O OBSERVA SEM COM ELE INTERAGIR, NÃO DEIXA, COM SEU TRAÇO MINORITÁRIO, DE CONSTITUIR UMA ATRAENTE VIA DE EXPRESSÃO PARA A NOVA GERAÇÃO DE POETAS BRASILEIROS, E COMO TAL É ABORDADA NESTE ARTIGO.
\end{abstract}

ABSTRACT: THE VISUAL PERCEPTION OF THE WORLD THAT SPREADS ITSELF IN DETAILS OF FORM, HUES AND MOVEMENT IS A RELATIVELY RARE FEATURE IN BRAZILIAN POETRY, AS OPPOSED, FOR INSTANCE, TO THAT OF NORTH AMERICA. THE ESCAPE FROM SUBJECTIVITY BY MEANS OF CREATING A GAP BETWEEN THE SEER AND THE SEEN, BETWEEN THE OBJECT AND THE POET-MACHINE WHO OBSERVES IT WITHOUT INTERACTING, REPRESENTS, HOWEVER, DESPITE BEING A MINORITARY FEATURE, AN APPEALING EXPRESSIVE RESOURCE FOR THE NEW GENERATION OF BRAZILIAN POETS AND IS AS SUCH APPROACHED IN THIS ARTICLE.

PALAVRAS-CHAVE: SUBJETIVIDADE - VISUALIDADE - POESIA BRASILEIRA - SÉCULO XXI KEY-WORDS: SUBJECTIVITY - VISUALITY - BRAZILIAN POETRY - $21^{\text {ST }}$ CENTURY 
despeito de um processo de depuração evidente ocorrido no século XX, a expressão da subjetividade na poesia brasileira mantém uma característica comum a toda a produção anterior: o menosprezo da visão e o uso da imagem quase que apenas como reflexo e metáfora da vida interior. Comparada com a poesia anglofônica, fortemente marcada pela fanopéia - termo de Ezra Pound para a expressão por imagens -, a brasileira (arrisco-me a dizer, tentativamente, a lusófona) dá à visão mais o estatuto de percepção extra-sensorial do que de apreensão física de formas, texturas e cores dadas aos olhos. Sem poder aqui explorar os primórdios dessa tradição, é interessante, porém, lembrar a desconfiança na visão como via de acesso ao conhecimento em Sá de Miranda ${ }^{1}$. Generalizações são inevitavelmente grosseiras, mas, a título de hipótese, parece-me lícito afirmar que, em contraste com o deleite no visível que, por exemplo, a literatura norte-americana demonstra, a poesia brasileira em poucos momentos apresenta a natureza e as coisas como um outro absoluto inapropriável pelo poeta.

O modernismo, entretanto, trará, com a emergência do cotidiano e dos ritmos da cidade na poesia, uma nova atenção para cenas e cenários, além do mero transporte do eu. Ainda assim, a cidade, ícone por excelência do moderno, não se mostra sempre como alteridade, seus múltiplos recortes funcionando muitas vezes como uma contrapartida da própria multiplicidade do eu lírico que deles se apropria - notadamente em Mário de Andrade. Contrasta com essa tendência geral uma parte da poesia modernista de primeira hora, em que ressalta um distanciamento irônico do visto: o poeta aponta - e não

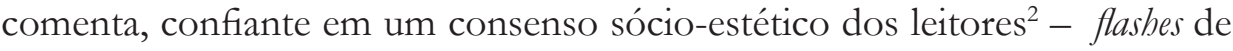
um cotidiano convencional e provinciano. Essa retirada de cena do eu, para deixar ver o não-eu indiferente ao poeta, inaugura um novo tratamento do objeto que será, a partir daí, recorrente na nossa poesia, até hoje. O presente se impõe como tema por oposição a um mundo intemporal de sensações, cobrando tributos do mais lírico dos poetas. Se em Oswald de Andrade a rendição ao camera eye é praticamente total, mesmo Mário, useiro em fundir-se com o visto, responde "presente" no seu "Rondó do tempo presente", colagem de fotogramas urbanos que atropelam o eu que os compõe.

\footnotetext{
1 Leve-se em conta aqui, naturalmente, o contexto de produção desse autor. Essa questão em Sá de Miranda é bastante complexa, e ficará aqui apenas como indicação.

2 Que, como comenta Pierre Bourdieu, no caso da poesia de vanguarda, tendem a ser seus próprios pares (cf. Bourdieu, As regras da arte, p. 281-282 e passim).
} 
Drummond, a maior e mais incontornável referência da poesia dos últimos cinqüenta anos no Brasil, teve seu "sarampão" oswaldiano nos anos 20, do qual "Cidadezinha qualquer" é produto. Deixando-se fortemente marcar pela contemporaneidade e pelo acontecimento do dia, Drummond tem no distanciamento irônico uma das mais insistentes de suas "sete faces", que convive, no entanto, com o nós engajado e participante ("vamos de mãos dadas") e com um lirismo banhado de subjetividade. Ao longo de sua obra prevalece o coração do poeta como medida do mundo ("mundo mundo vasto mundo"). É até essa imersão na própria sensibilidade que lhe faculta divisar a máquina do mundo - sintomaticamente, para recusar sua revelação: "baixei os olhos, incurioso" é quase um emblema da recusa da exterioridade. Apesar da prevalência da subjetividade, a poesia de Drummond é inquieta o bastante para nos fornecer toda a paleta que vai desde a recusa da exterioridade até o recuo do eu diante da concretude alienada das coisas. O exemplo extremo é "Jornal de serviço", com suas enumerações retiradas das "páginas amarelas"”.

A representação típica da concretude na poesia recai na palavra "pedra", a coisa por excelência que inspirou também a artista plástica Lygia Clark. Dois dos maiores poemas brasileiros (de fato, incluídos na seleção de Ítalo Moriconi $^{5}$ ) dedicam-se a explorar esse referente; o de Drummond construindo a pedra como obstáculo, o de João Cabral como esfinge de eloqüente silêncio. Por ser um ícone da permanência, a pedra permite ao poeta, em dicção moderna, interrogar a essência eterna da poesia. Em Drummond, a ênfase é colocada sobre a impressão deixada nas retinas, e daí na memória, do poeta. É a pedra para si. Em João Cabral, a pedra está fora e dentro: fora para o observador urbano, imerso na modernidade, e dentro para o sertanejo, que com ela se consubstancia de forma pré-racional. Pedra para si e em si. Essa funcionalização da pedra a retira da categoria de coisa para inseri-la na cultura - memória, em Drummond, educação em Cabral.

As duas lições da pedra vão informar de maneira duradoura a poesia posterior. Seja em poemas em que a pedra é explicitamente nomeada, seja naqueles em que há de algum modo uma interrogação das coisas, muitos poetas

\footnotetext{
3 Procedimento já utilizado por Oswald de Andrade em "Biblioteca nacional".

4 Os exemplos são encontráveis em poemas de diversas línguas, incluindo "wort stein", de Ernst Jandl, e "Le galet", de Francis Ponge.

5 Os cem melhores poemas brasileiros do século.
} 
contemporâneos buscam - em algum momento de suas obras - espreitar e apreender a essencialidade do visto. Excepcionalmente, Manoel de Barros propõe o caminho inverso: "Adoecer de nós a Natureza: / botar aflição na pedra" ("Uma didática da invenção"). A atitude de espreita obriga à atenção, à condensação da escrita e à representação da espera pela preservação do branco da página. Tal depuração se percebe também no olhar voltado para a paisagem, quanto esta deixa de ser um mero reflexo da subjetividade que olha, mantendo-se neutra diante do observador.

O caso mais freqüente é o de uma certa interação entre mente - e/ou corpo - e paisagem. Uma seqüência de quatro poemas de Ronald Polito ${ }^{6}$, por exemplo, mostra diferentes graus de envolvimento com o cenário, culminando na autonomia deste em "Antediluviano": "águas / um relâmpago aguarda / o céu / de ar preciso"7. Matéria e paisagem, de Júlio Castañon Guimarães, dá ênfase à disciplina do olhar e conseqüente apagamento do eu. Donizete Galvão explica essa tendência: "o corpo necessita dos objetos / para que estes confirmem / sua existência em fuga" ("Os homens e as coisas"). Já Duda Machado desmascara a espreita da natureza e das coisas como busca da alteridade, que acaba se revelando mero instinto predatório. "Devoração da paisagem", começando pela aparentemente inocente contemplação de um "cromo", reverte-se em rapinagem:

De algum lugar, distante da retina, a fera irrompe e de pronto

a paisagem se contrai.

Já é presa, repasto de significados com que a fera realimenta sua fome. (MACHADO, 1997)

\footnotetext{
Publicada no primeiro número da revista Inimigo Rumor.

Considere-se aqui a influência da poesia oriental, fortemente imagética.
} 
Até aqui permanecemos na linha geral prenunciada por Drummond ${ }^{8}$ e Cabral - recolhimento, depuração e rigor. Uma outra linha mestra, no entanto, vem nas últimas décadas informando a nova poesia brasileira: a precisão e o detalhamento na apresentação do visto pelos poetas norte-americanos. A "pintura por palavras" é característica marcante dessa poesia que, por muito tempo, foi pouco visitada pelos nossos poetas. A união do espírito prático com a poesia (que Marianne Moore definiu como "jardins imaginários contendo sapos de verdade") chega a se exprimir em posições extremas como a de Robinson Jeffers, que considera uma degradação toda inscrição de sentimento no mundo: "todas as artes perdem virtude / Ante a realidade essencial / De criaturas tratando de sua vida em meio aos igualmente / Severos elementos naturais" ${ }^{\prime \prime}$.

O deleite no visual, da forma como aparece em tanto da poesia norte-americana, encontra poucos adeptos em território brasileiro, no qual um poema como o "Javali", de Hermínio Bello de Carvalho (Embornal), é um exemplo raro. Mais comumente, a influência daquela poesia em nossa produção vem matizada pela lição modernista, antes fotográfica que descritiva. $\mathrm{O}$ "poder silencioso" do objeto, ainda ao modo cabralino e drummondiano de encontro com a pedra, é sentido no processo de sua transformação, propõe Horácio Costa: "Eis-me aqui procurando em tua re-forma / Teu trabalho anterior, tua sombra / Que se alongou em minha memória tua" "“Transformação do objeto”). Nem em Paulo Henriques Britto, tradutor da visualíssima Elizabeth Bishop, a primazia da visão é um aspecto relevante, mesmo porque, diz ele, "nenhum descobridor na história / (e algum tentou?) jamais se desprendeu / do cais úmido e ínfimo do eu" ("Sete poemas simétricos").

Algum tentou. Em uma espécie de "vida secreta das coisas", Sérgio Medeiros volta-se radicalmente para um procedimento que aqui chamarei de "dêitico" e que o próprio poeta classifica como "descritos". Por "dêitico" entendo aqui o que se refere ao gesto de apontar, quase em oposição ao uso lingüístico do termo, cujos referentes seriam os pronomes de primeira e segunda pessoa

\footnotetext{
8 Embora, como foi dito, haja vários Drummonds. Para uma leitura mais ampla da poética drummondiana, ver Santiago, Silviano, "Convite à leitura dos poemas de Carlos Drummond de Andrade", em Ora (direis) puxar conversa!

9 Tradução de Mário Faustino, 1985.

10 Tradução de Paulo Vizioli, 1976.
} 
e as expressões que fazem supor o presente da enunciação. Digo "quase" porque também no caso dos "descritos" o momento é sempre o presente e as coisas apontadas estão diretamente diante do olhar. Esse olhar, entretanto, se despersonifica ao se transformar em aparelho ótico, binóculo ou luneta ${ }^{11}$. Embora naturalmente se possa pressupor uma consciência que assesta as lentes na direção pretendida, essa não cria uma relação entre si e o visto. Não se trata, porém, de um cenário estático. O espectador assiste de longe a uma animada festa na qual não toma parte. As coisas movem-se, crescem, diminuem, saltam, contorcem-se, interferem umas com as outras. No poema " $\mathrm{O}$ alongamento", a luz, o vento e a água são protagonistas do espetáculo, que obriga o binóculo ou a câmara a reajustar seu foco a cada passo:

[503cm]
eucaliptos
violentos
lincham o vento;
depois,
o pó
se assenta.
[539cm]
o vento sul
se contorce
como mangueira
jorrando certo
e inesperado
[106cm]
o reflexo
da escada esquelética
e brilhante
da piscina

11 Ronald Polito tem um poema intitulado "Luneta" que ilustra bem a idéia: "3 árvores / 2 nuvens / 1 montanha". 
- grande clipe -

prende a folhagem

no vento

(MEDEIROS, 2004)

"Paisagens imaginárias dum jardineiro doudo" descreve um grupo de palmeiras em diversos estágios de interação com os elementos ao longo do dia. As imagens são precisas, desenháveis, resolvendo-se muitas vezes em símiles animais que as tornam ainda mais pictóricas, mas dão às palmeiras um ar de distância orgulhosa do espectador, apesar do clima levemente patético das cenas:

** - na floresta de palmas baixas erguem-se as pernas gigantes

das palmeiras adultas saindo do ninho

********* - as palmas estraçalhadas se dirigem para o vidro (da janela) sem tocá-lo: pausas no ar, os braços longos e duros, deformados, são pacíficos e verdes; ou, secos e pálidos, o braço e a palma caem como esqueleto de bruços $* * * * * * * * * * * * * * * * * * * * * * * * * * * * * * * * * * * * * * * * *$

(...)

************** - a palmeira verde lança sua sombra: no gramado: como enorme tartaruga que nadasse imóvel no fundo viscoso de uma água clara $* * * * * * *$ $* * * * * * * * * * * * * * * * * * * * * * * * * * * * * * * * * * * * * * * * * *$

(...)

****************** a sombra friorenta veste meia negra na palmeira: outros caules se despem, cinzentos, algo pálidos $* * * * * * * * * * * * * * * * * * * * * * * * * * * * * * * * * *$ $* * * * * * *$

(MEDEIROS, 2004)

Antropomorfizados, plantas, objetos e elementos são como pessoas indiferentes e insensatas, que não se deixam interrogar do ponto de vista da razão. Os sinais tipográficos (colchetes, asteriscos, travessões, barras, reticências) 
concorrem com sua fria inexpressividade para criar o distanciamento de um sentido reunificador. Assim, a natureza, que para Wordsworth e os românticos em geral proporcionava uma comunhão com o sublime, perde toda a sua atmosfera edificante para se alinhar aos mais triviais objetos do cotidiano - saco plástico, boné, lata, ralador, durex - e com eles compartilhar uma opacidade autocentrada. O procedimento lembra o mestre do nonsense inglês, Lewis Carroll, que parodiou exatamente poemas de Wordsworth, introduzindo na poesia, em meados do século XIX, nomes de produtos anunciados nos reclames de jornal da época. "A canção do jardineiro louco" de Carroll mostra, em estrofes reiterativas, a confusão do olhar desse personagem, que pensava ter visto uma coisa e depois percebe que se tratava de outra inteiramente diferente (ambas, entretanto, igualmente corriqueiras e dessublimadas) ${ }^{12}$.

Nessa radical impermeabilidade das coisas, que só se podem apontar, não tocar ou possuir, mais uma vez é o presente e seus avatares que provocam o retraimento do eu. $\mathrm{O}$ windsurfe, as cadeiras de praia e a piscina, constantemente atravessando a poesia de Medeiros, reduzem todos os componentes naturais a objetos de cena montados para um olhar turista, descompromissado. A idéia de colagem aí vem menos de referências eruditas do que do acúmulo de mercadorias compradas e por comprar que se expõem ao passante por toda parte. Aglomeradas como na banca de revistas ("Alegria, alegria", de Caetano Veloso) ou salpicadas pela paisagem (esta também bem de consumo), as coisas apontadas refletem o desencantamento do mundo. O jardineiro de Carroll, ao contrário do "descritor" de Alongamento, não podia assistir ao desencantamento do mundo sem exclamar sua consternação: "At length I realise, he said / the bitterness of life". A posição de voyeur que o poeta assume na poesia de Medeiros implica uma quase inveja das coisas, antes do temor da própria coisificação.

Nos poetas em que a visão inclui o trazer a si da imagem, que penetra a retina e sofre uma reordenação pelo sujeito, antes de se fixar como escrita, não se abdicou ainda da instância metafísica. Mesmo nesses, porém, o presente não deixa de aparecer sob a forma da multiplicidade e da alteridade que escapam à apropriação. Já no The waste land de Eliot, o detalhe vulgar, a corruptela e a sordidez invadem o poema (que por outro lado é repleto de referências

12 Para uma leitura desse poema, ver meu livro Rima e solução, p. 139-149. 
elevadas) como um lastro que o impede de alçar vôo. Uma terceira posição, além da luta pela existência, mesmo que "em fuga", do eu, e distante também do alheamento nonsense de Medeiros, pode ser encontrada nos "sonetos salvajes" de Douglas Diegues, que escreve em portunhol, guarani e outras línguas da fronteira Brasil/Paraguai.

Tomando a forma soneto - tão revisitada hoje - e retirando-lhe exatamente o rigor formal, Douglas a transforma em uma espécie de saco de lixo do cotidiano. Escolhe o soneto shakespeareano, que termina em dístico de caráter - em Diegues - francamente sentencial, lembrando de novo o "jardineiro louco" de Carroll com suas exclamações patéticas ao fim de cada estrofe. Outsider radical na paisagem urbana, o eu que se enuncia nos poemas de Diegues também não se recolhe a um mundo próprio que filtra as projeções do exterior. É interessado entre os alheios, ouvinte atento entre surdos, curioso diante do déjà $v u$. Exibe uma auscultação do mundo que não se restringe à visão, mas que reduz ao mínimo a reelaboração desse pela subjetividade, traduzindo-se em seqüências enumerativas:

belleza pública bersus belleza íntima

belleza bisible bersus belleza que ninguém bê

belleza dolarizada bersus belleza gratuita

beleza cozida bersus belleza frita

belleza antigua bersus belleza nova

belleza viva bersus belleza morta

belleza magra bersus belleza gorda

belleza em berso y en prosa

belleza salbaje bersus belleza civilizada

belleza di dentro bersus belleza di fora

belleza rápida bersus belleza que demora

belleza simples bersus belleza complicada

este mundo está ficando cada vez mais horrible

quase ninguém consegue mais ver la belleza invisible

(DIEGUES, 2002) 
As "flores do mal" desse jardineiro louco são, de certa forma, os antípodas das palmeiras de Medeiros, patéticas e altivas, submissas e autônomas. Nos sonetos "salvajes" de Diegues, os rótulos e embalagens tornaram-se a própria coisa, em cidades "barbie" repletas de "prazos oficiales toxinas animales crimes banales", contra as quais o poeta lança invectivas sem resposta. A inoperância do humano não leva, como em Medeiros, à busca da vida inteligente no planeta das coisas. Estas são, nos sonetos, meros sucedâneos decadentes do próprio humano decadente, vistos com isenção mas curiosidade pelo poeta:

ellos preparam el defunto

como si preparassem a un artista

ou a una ensalada mista

después penteiam para que o mesmo non fique com ar de presunto

y comezan a encher u caixón de flores

como dos jardineros - o dois atores

profissionales, espontâneos, y u presunto

parece agora un ready-made, jardim, instalazione, menos defunto

y também, parece, o presunto, sentir-se legal

deitado en aquele mar de flores

pronto para partir para além du bem y du mal

deixando para trás este paraíso de horrores

ellos preparam u presunto

como se estibiessem preparando um omelete - non un defunto

(DIEGUES, 2002)

No entanto, nem todo corpo de sonetos "salvajes" exibe esse grau de desencantamento. Há momentos de nostalgia e lirismo, que só a parataxe ainda radical mantém sob controle. Por outro lado, a presença constante do eu e do você nesses poemas não garante a sobrevivência da subjetividade, já que eu e você, como personagens de Beckett, só se dão através da ação imediata e escancarada que a rapidez da cidade exige. O panfletário assume aí uma feição interessantemente kitsch: acaba por ser o correlato da retórica publicitária que 
assola os ouvidos e os olhos do passante urbano ("invente, ouse, inove, chute a gol, no perca mais este dia/ faça você mesmo sua própria antologia"). No todo, os sonetos dieguianos têm um ar de inusitado pela naturalidade da colagem que apresentam, a concepção do poeta como ser basicamente gregário que busca o convívio impossível com sua raça (mas agora sem vida interior que compense seu isolamento) e o estranhamento que instalam nas coisas mais usuais. O mesmo distanciamento beckettiano aparece também em uma parte da produção de Sérgio Medeiros, que consiste em formas pré-, pós- ou pseudodramáticas autodenominadas “ópera, balé, réquiem, pantomima”, nas quais os personagens estão, mais do que de autor, em procura de um roteiro. Juntos, Medeiros e Diegues dão considerável impulso a uma tendência minoritária na poesia brasileira. Se dividirmos os procedimentos estruturantes da poesia moderna e contemporânea brasileira em quatro tipos: 1) reflexão metalingüística sobre a palavra e o discurso, 2) intertextualidade preponderantemente voltada para referências literárias (inclua-se aqui a paródia), 3) exploração sutil da subjetividade e seus meandros, 4) recorrência à imagem e à sua emulação (fotográfica, cinematográfica, pictográfica), certamente o último representará o veio menos explorado. Esse fato por si só justifica a atenção que demos aqui a esse traço recessivo e a dois novos poetas que o redesenham cada um à sua maneira, de forma absolutamente pessoal.

A caracterização desses modos de formar como dêixis e estranhamento visa sublinhar neles a presentificação do objeto e da máquina-poeta que o observa e a total impossibilidade de comunhão entre vedor e visto. Modos já visitados pela vanguarda internacional em diversos momentos e vieses da modernidade, sua retomada terá sempre algo de paródico, retirando dessa reapresentação todo ranço de iconoclastia. Se nesses versos ressoa algo de oswaldiano, o tom provocativo será sempre mediado pela reafirmação do princípio de direito à pesquisa que Mário de Andrade destacou como a grande contribuição do modernismo.

\section{Referências Bibliográficas}

ANDRADE, Carlos Drummond de. Poesia e prosa. Rio de Janeiro: Nova Aguilar, 1979. ANDRADE, Mário de. Poesias completas. São Paulo: Círculo do Livro, s/d. 
ANDRADE, Oswald de. Pau-Brasil. São Paulo: Globo, 2000.

ÁVILA, Myriam. Rima e solução. A poesia nonsense de Lewis Carroll e Edward Lear. São Paulo: Annablume, 1996.

BISHOP, Elizabeth. Poemas do Brasil. Trad. Paulo Henriques Britto. São Paulo: Companhia das Letras, 1999.

BOURDIEU, Pierre. As regras da arte. Trad. Maria Lúcia Machado. São Paulo: Companhia das Letras, 1996.

COSTA, Horácio. 28 poemas / 6 contos. 25 anos. Rio de Janeiro: Espectro Editorial, 2006.

DIEGUES, Douglas. Dá gusto andar desnudo por estas selvas. Sonetos salvajes. Curitiba: Travessa dos Editores, 2002. . Uma flor na solapa da miséria. Buenos Aires: Eloísa Cartonera, 2005.

FAUSTINO, Mario. Poesia completa/poesia traduzida. São Paulo: Max Limonad, 1985. GUIMARÃES, Júlio Castañon. Poemas (1975-2005). São Paulo/Rio de Janeiro: Cosac Naify/7 Letras, 2006.

MACHADO, Duda. Margem de uma onda. São Paulo: Ed. 34, 1997.

MEDEIROS, Sérgio. Alongamento. São Paulo: Ateliê Editorial, 2004.

MORICONI, Ítalo (Org.). Os cem melhores poemas brasileiros do século. Rio de Janeiro: Objetiva, 2001.

POLITO, Ronald. Solo. Rio de Janeiro: Sette Letras, 1996.

.Vaga/Dado/Antediluviano/Muda. Inimigo Rumor, Rio de Janeiro, n. 1, jan./ abr. 1997.

PINTO, Manuel da Costa. Antologia comentada da poesia brasileira do século 21. São Paulo: Publifolha, 2006.

SÁ DE MIRANDA, Francisco de. Obras completas. 2 v. Lisboa: Sá da Costa, 1942. SANTIAGO, Silviano. Ora (direis) puxar conversa! Belo Horizonte: Ed. UFMG, 2006. VIZIOLI, Paulo. Poetas norte-americanos. Antologia bilíngüe. Rio de Janeiro: Lidador, 1976. 